\title{
Squash Hall Indoor Temperature Monitoring System Based on LabVIEW Design
}

\author{
Dongjin Xian'1, Xufeng Gu¹, Jinfeng Chen² \\ ${ }^{1}$ School of Physical Education Changzhou University, Changzhou, China \\ ${ }^{2}$ Changzhou Liu Guojun Vocational Technology College, Changzhou, China \\ Email: xdj@cczu.edu.cn
}

How to cite this paper: Xian, D.G., Gu, X.F. and Chen, J.F. (2017) Squash Hall Indoor Temperature Monitoring System Based on LabVIEW Design. Journal of Computer and Communications, 5, 52-61. https://doi.org/10.4236/jcc.2017.58004

Received: May 2, 2017

Accepted: June 10, 2017

Published: June 15, 2017

Copyright (C) 2017 by authors and Scientific Research Publishing Inc. This work is licensed under the Creative Commons Attribution International License (CC BY 4.0).

http://creativecommons.org/licenses/by/4.0/ cC) (i) Open Access

\begin{abstract}
By Using ADAM4000 series data acquisition module, squash hall monitoring system was developed based on the LabVIEW platform. The system consists of master control, signal channel, file operations, digital filtering, spectral analysis, statistic analysis, system monitoring and other modules. The system will alarm at the real time when the result of the average temperature of the squash hall divided by ten is no less than the monitor threshold of 4.3 while athletes are playing squash, by which the temperature and pressure data acquisition, processing and monitoring could be achieved. Application shows that the changes of human exposure temperature between $20^{\circ} \mathrm{C}$ and $43^{\circ} \mathrm{C}$ can achieve the comfort level of athletes' movement, proving that the monitoring system effectively improves the security of squash hall indoor temperature environment.
\end{abstract}

\section{Keywords}

Athletes, Squash Hall, LabVIEW, Indoor Temperature, Monitoring System

\section{Introduction}

Scientists did the experiment on the highest temperature which the human body can endure in the dry air environment: human body can endure for one hour in environment of $71^{\circ} \mathrm{C} ; 49$ minutes in environment of $82^{\circ} \mathrm{C}$; and only 26 minutes in the environment of $104^{\circ} \mathrm{C}$. The upper limit of normal humans' armpit temperature is usually $37.4^{\circ} \mathrm{C}$. It will up to $43^{\circ} \mathrm{C}$ when in fever. The temperature would be controlled below $43^{\circ} \mathrm{C}$ in order to keep the comfort and strength of athletes when athletes in playing squash [1] [2] [3]. However, the ventilating system of the existing squash hall room is almost normal air conditioning temperature control system. There is no real-time temperature monitor inside. To move the traditional temperature test instrument inside is obviously unpractical. 
[4] So we need to design a monitoring system for testing the squash hall indoor temperature and guiding the operating personnel in order to keep the strength of athletes. The temperature monitoring of squash hall must use advanced and reliable equipment. But compared to virtual instruments, the advantages of traditional instruments on many aspects of data collection, data storage, filtering methods, data analysis and real time monitoring are not clear. By introducing the virtual instruments into the real-time monitoring system on squash hall and collecting and processing the field data, we can provide athletes with the dynamic situation of squash hall by many ways, such as by real time trend curve or alarm. Staffs can operate in time according to the curve or alarm prompt. This system can collect and monitor the environment temperature and its differential pressure by using devices, such as LabVIEW2009, sensor, PLC and data collection module to achieve the purpose of strict monitoring of athletes at sports.

\section{The General Design of the System}

\subsection{The Structure Design of Squash Hall}

To conform to the standard of squash courts use, squash hall consists of the wall system, floor system, glass back wall system, lighting system and ventilation system. The standard court stipulated in the international federation of squash game are divided into the singles and doubles play. The length of the singles court is 9.75 meters, width is 6.4 meters, height is 4.57 meters while the length of the doubles court is 13.72 meters, width is 7.62 meters and height is 6.1 meters (The floor plan is shown in Figure 1, and perspective is shown in Figure 2). But the squash hall of the United States is smaller, with its width of 5.64 meters and height of 4.88 meters. Venue and the audience will provide a set of ventilation system to ensure four times per hour full air conditioning, heating, ventilation,

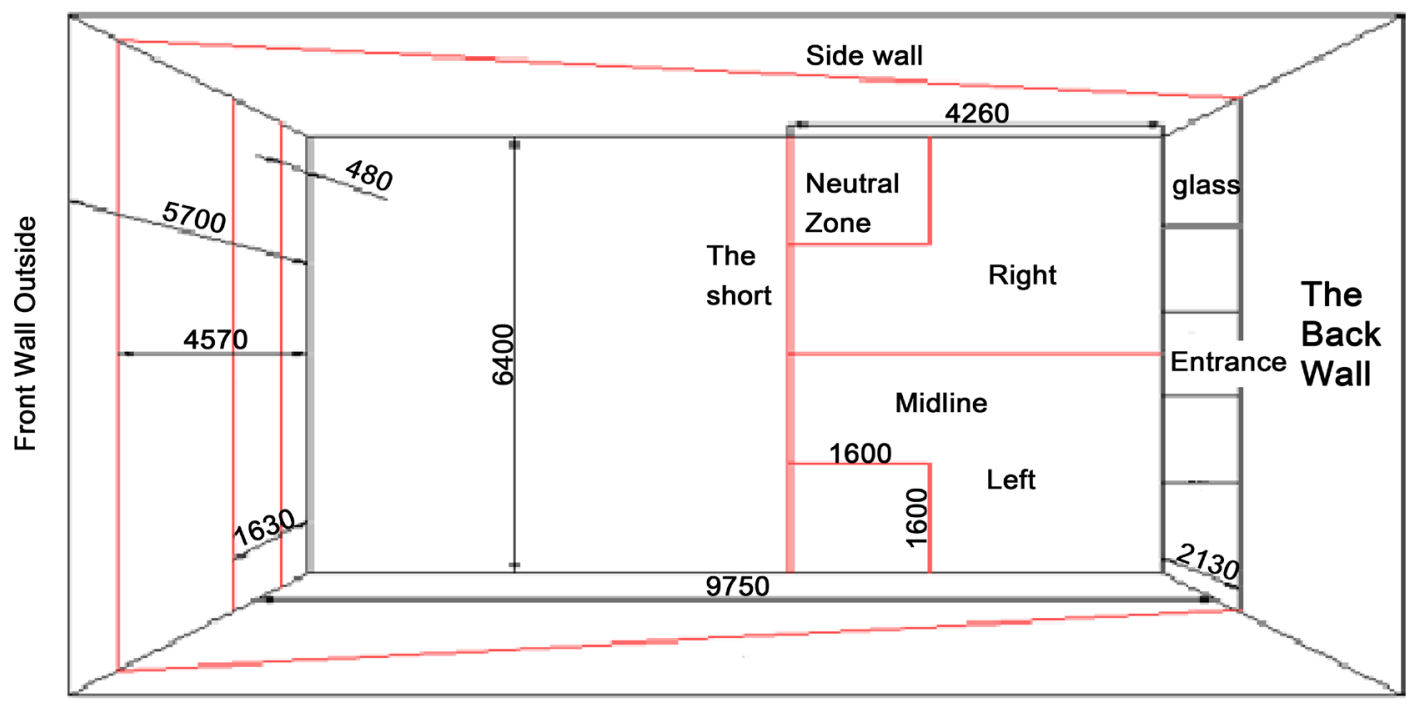

Squash Hall Plane Size Chart

The Unit: $\mathrm{mm}$

Figure 1. Squash hall floor plan. 


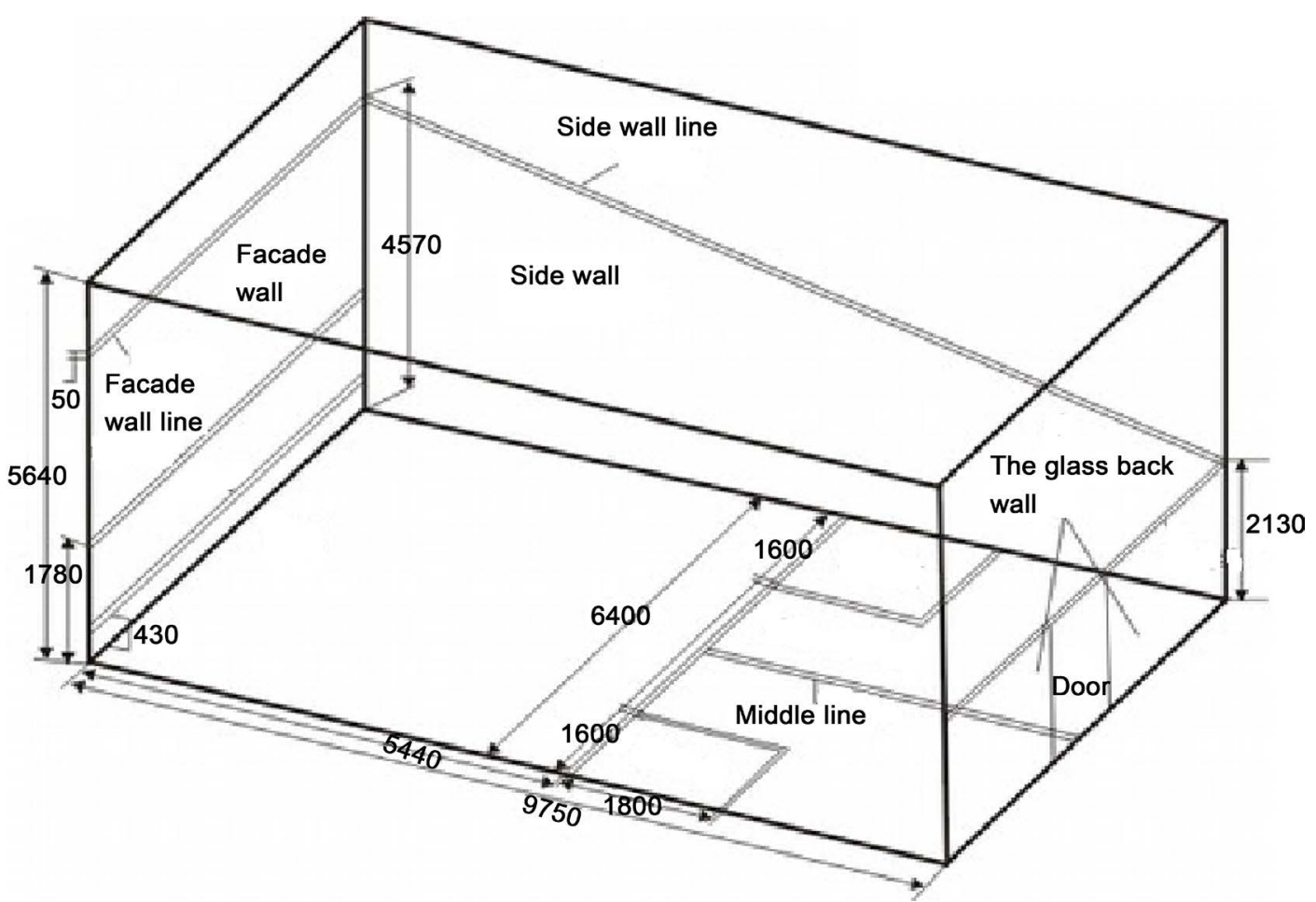

Figure 2. Squash game pavilion perspective.

and any portion of the other facilities is not allowed to highlight in site unless the facility can meet the following requirements: 1) Each part of the facilities higher than a level surface is no more than $5400 \mathrm{~mm}$; 2) Each highlight part of the facilities in space is no more than $150 \mathrm{~mm}$; 3) There is no shadow projected on the front wall. Besides, there is all glass type squash hall (as in Figure 3). The all glass type squash hall is easy to watch and remove with novel and lively appearance, and it is easy to install and more suitable for small venues and temporary needs.

\subsection{The Squash Hall Data Acquisition System}

First is to open the power and light control system of squash hall, in order to secure the electricity effectively and brightness. When athletes began to exercise, the hot air produced by the hot air system first goes to the duct, then goes to the front wind room of the squash hall by the front wind board, then goes to the back wind chamber through the front wind board, and is discharged into the air duct by the ventilation door. The hot air in the air duct enters another squash court by another warehouse under the ventilation door, then goes to the top wind chamber by back wind board, squash hall and front wind board, then is discharged from the wet platoon. The operation personnel should watch frequently the key parameters such as the temperature, humidity and wind pressure of air channel and all squash halls when athletes are playing, and they should test samples from the sampling window regularly, and adjust the equipment of boiler, fan, air door and the wind close curtain. Then they should keep the temperature when the indoor temperature is adjusted to the objective humidity. The squash 


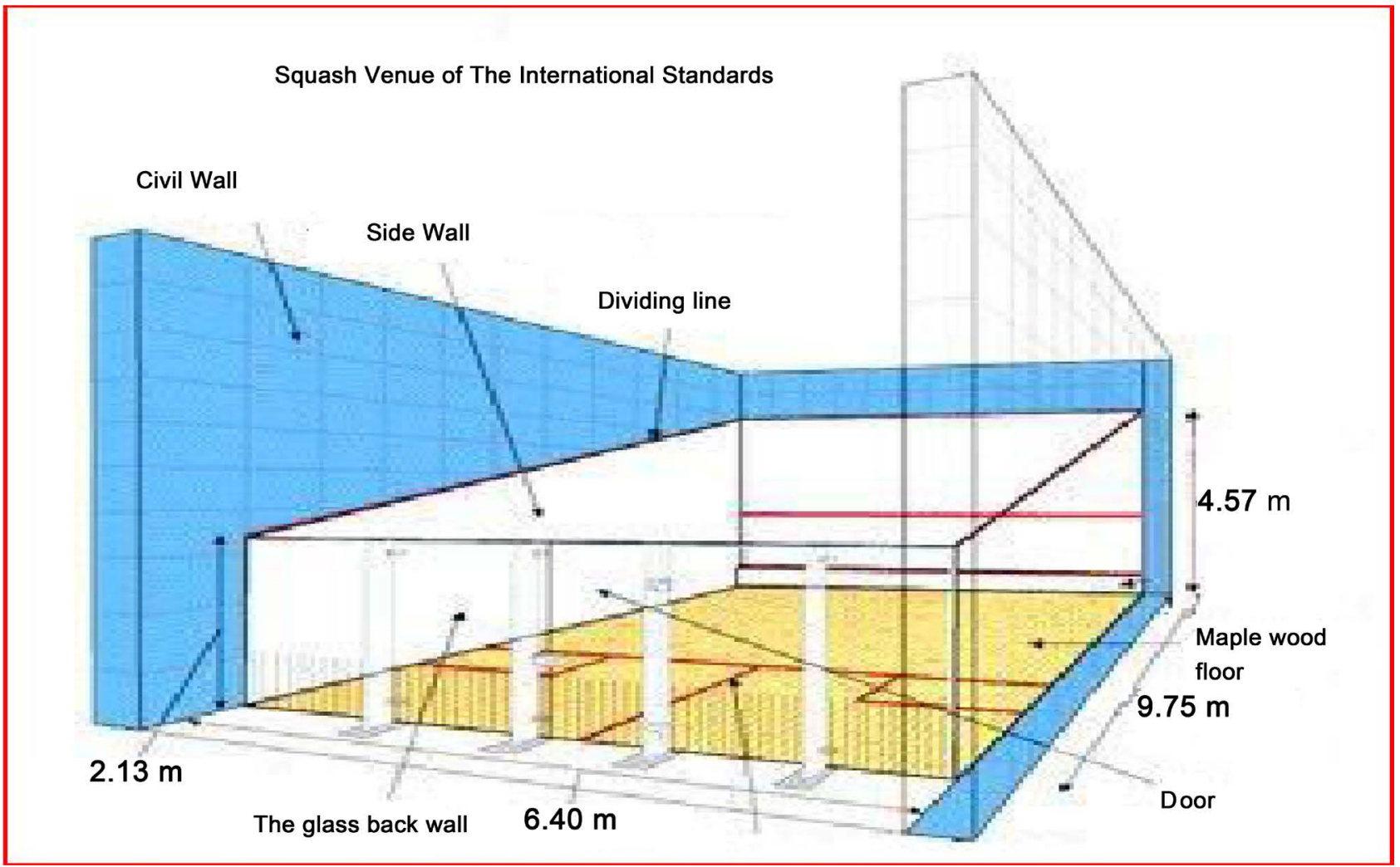

Figure 3. Full glass type squash pavilion.

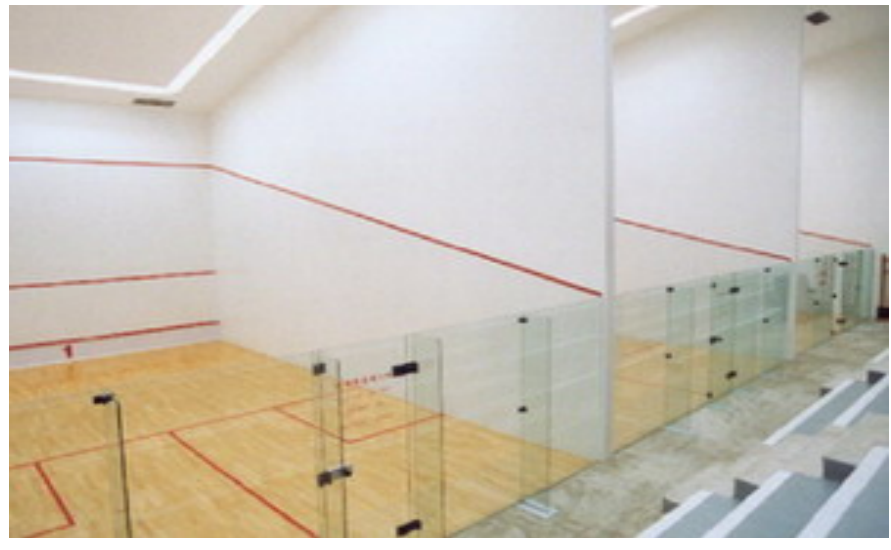

Figure 4. Squash hall overall modelling figure.

hall overall modeling is shown in Figure 4.

\subsection{The Overall System Design}

The system collects directly the data tested by field temperature and pressure sensors by data collecting module, then sends to industrial control by RS485, and analyze and process the data by using LabVIEW, to monitor the production status. Send the analyzed results to PLC and then PLC will be in charge of operations of start-stop and reversing control of fan. The system will be divided into three levels including the manage level, the monitor level and the spot level generally. The system whole frame diagram is shown in Figure 5. 


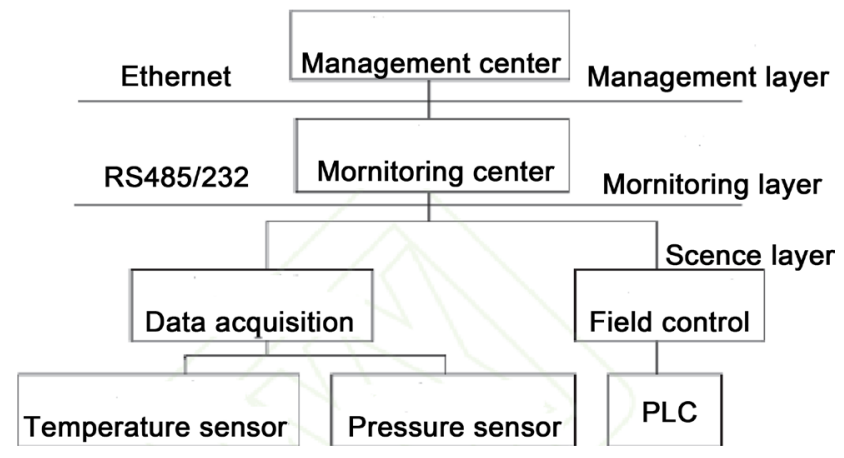

Figure 5. Diagram of the system as a whole.

\section{The Hardware Composition of Indoor Temperature Monitoring System}

1) Temperature sensor: The system selects the platinum resistance temperature sensor, sets a temperature sampling points outdoor, and install respectively industry sheathed type three wire heating resistor, and lays equably three temperature sensors as sampling site in the upper and lower wind tunnels. 2) Pressure sensor: The system chooses STP pressure sensor. It sets one pressure sampling site to calculate the inside and outside pressure difference of the wind channel. 3) Data collecting module: The temperature collecting module uses ADAM-4015 of Advantech company, and pressure collecting module uses ADAM-4117 of Advantech company. Data collecting module follows the RS485 communication protocol. 4) Communication module: The system chooses ADAM-4520 which can communicate with industrial computer directly. 5) System monitor center: The system monitor center chooses the standard industrial control IPC-610H of Advantech company, the standard of RS485 transmits the different data and control signal. ADAM-4520/4522 isolating converter can convert RS232 signal and RS485 signal transparently.

\section{The Software Design of Squash Hall Temperature Monitoring System}

\subsection{The LabVIEW2009 Software}

The LabVIEW2009 software adopted by this paper is an instrument which can replace the traditional instrument when a computer and the outside port (such as the computer COM port, LPT port, or board) are under the software control. The system can meet the requirements for PC monitoring interface and data analysis, and it communicate data with PLC or intelligent module through the regular communication interface (such as the way of serial port and USB). The flow chart is shown in Figure 6. First is to design the integrated system and determine the overall plan, choose and install the software LabVIEW2009. Then set the project file according to the true environment. The file could be divided into two parts: one is the front control panel and the other is electronic design. The operator should understand the composition of the control panel, and will operate when it is in need. The two parts from the system together to moni- 


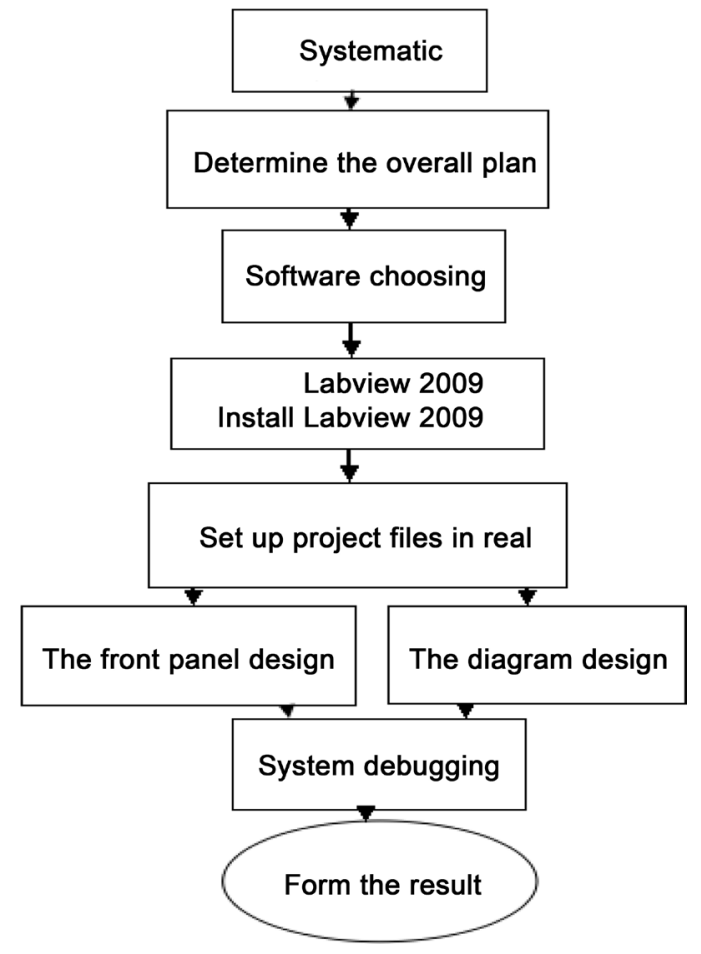

Figure 6. Software system overall flow chart.

tor the temperature.

\subsection{The Composition of the Software System}

The system consists of main control, signal channel, file operations, digital filtering, spectrum analysis, statistical analysis module and system monitoring module. The main monitor interface of squash hall temperature: It is mainly used to show the status, temperature and pressure of all squash halls, and the difference of the upper and lower air duct pressure. Combining with the realtime curve plotting function of LabVIEW2009, it displays real-time state of each variable dynamically, including temperature and pressure of all squash halls, and the difference of the upper and lower air duct pressure. It mainly shows the real-time temperature curve and pressure curve inside the squash hall, and displays data changes in the form of oscillogram and histogram intuitively. When the temperature monitoring threshold exceeds 4.3 , the system will alarm and the corresponding alarm lights will start flashing, at the same time alarm Windows pop up. At this time, the staffs need to adjust the air conditioning power system in order to achieve comforts of athletes. The squash hall indoor temperature monitoring interface diagram is shown in Figure 7.

\subsubsection{The Main-Control Module}

The main-control module is the top of the whole software, and it will control, call, organize and coordinate each module to finish the data analysis and test control.

\subsubsection{The Signal Channel Module}

This module puts pressure and temperature data into function by index data in 


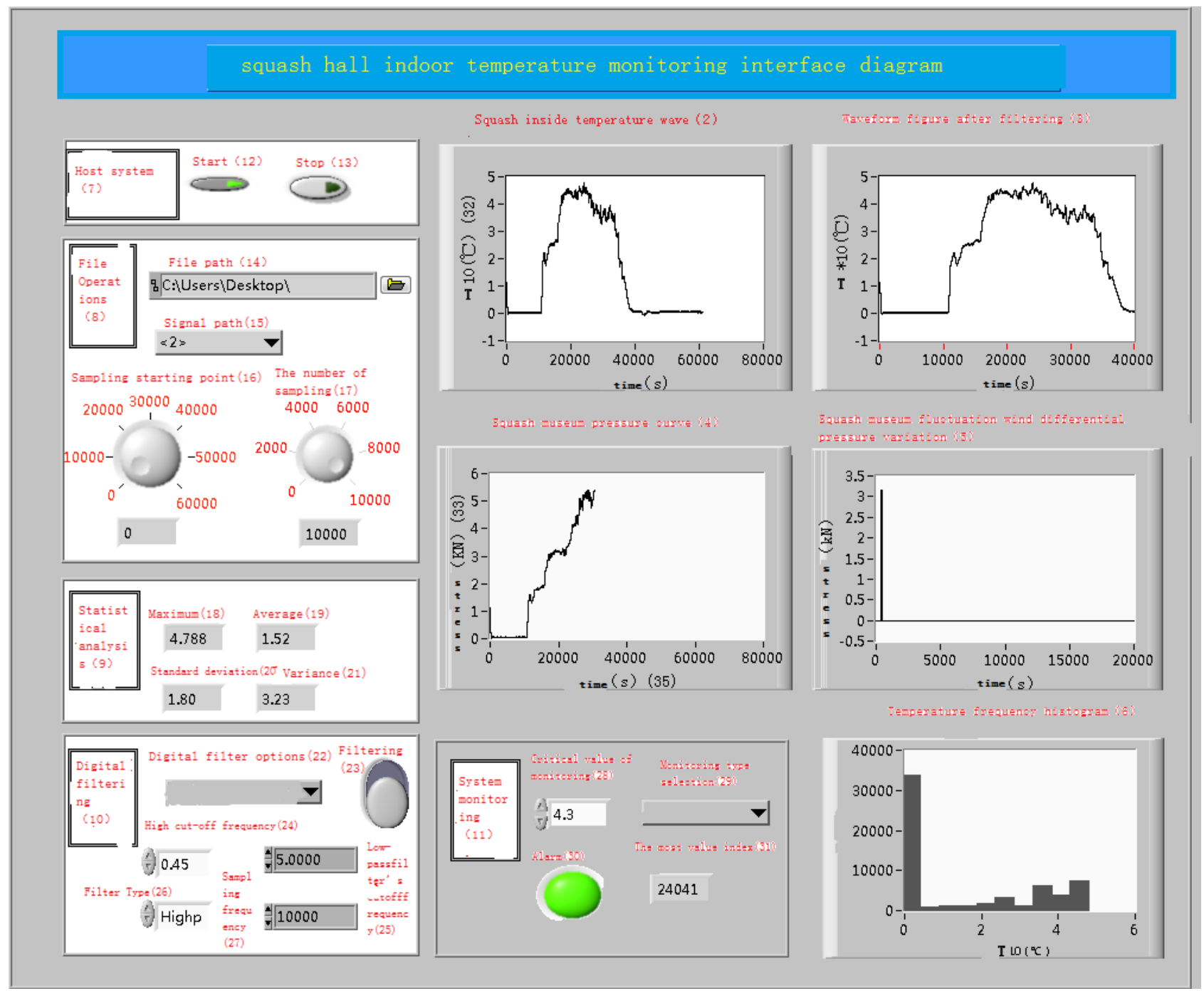

Figure 7. Squash hall indoor temperature monitoring interface diagram.

two signal channels. The attachment plate can show the default data type of the polymorphic function.

\subsubsection{The File Operations Module}

This module is mainly composed of the file path and signal channel. It inputs function through the sampling number and sampling start point.

\subsubsection{The Digital Filter Module}

This module is to filter the temperature signal and only pass signals in specific spectrum. It selects more accurate temperature data to draw curves by filters, and it can provide the system with accurate temperature change status. From Figure 7, we can know that the temperature waveform figure is more subtle after the data is filtered.

\subsubsection{Spectrum Analysis Module}

From the squash indoor pressure curve and squash court fluctuation of leeway pictures in Figure 7, we can see that the system has not started at the beginning. 
The squash indoor pressure is 0 , and it gradually increases when the fan starts running. When the indoor temperature reaches balance, the pressure change rate decreases gradually, which reflect the indoor temperature status.

\subsubsection{Statistical Analysis Module}

(Histogram.VI) calculates the maximum temperature data, the variance, mean and standard deviation. It uses LabVIEW to design software which analyzes the temperature data samples and it analyzes and displays the histogram of the measured data (samples). The mean value, variance and standard deviation are three basic statistical parameters. The mean value reflects the temperature average level, and the variance and standard deviation show the temperature deviation from the mean value.

\subsubsection{Monitor System Module}

When athletes are playing, the indoor temperature has bigger influence on the athletes' comfort, which requires the indoor temperature be controlled lower than $43^{\circ} \mathrm{C}$. The system will alarm or pop up alarm window at the real time when the result of the average temperature of the squash hall divided by ten is no less than the monitor threshold of 4.3 while athletes are playing squash. At this time, the staffs need to adjust the dynamic system of air conditioning to achieve indoor temperature balance. The squash hall indoor temperature monitor program is shown in Figure 8.

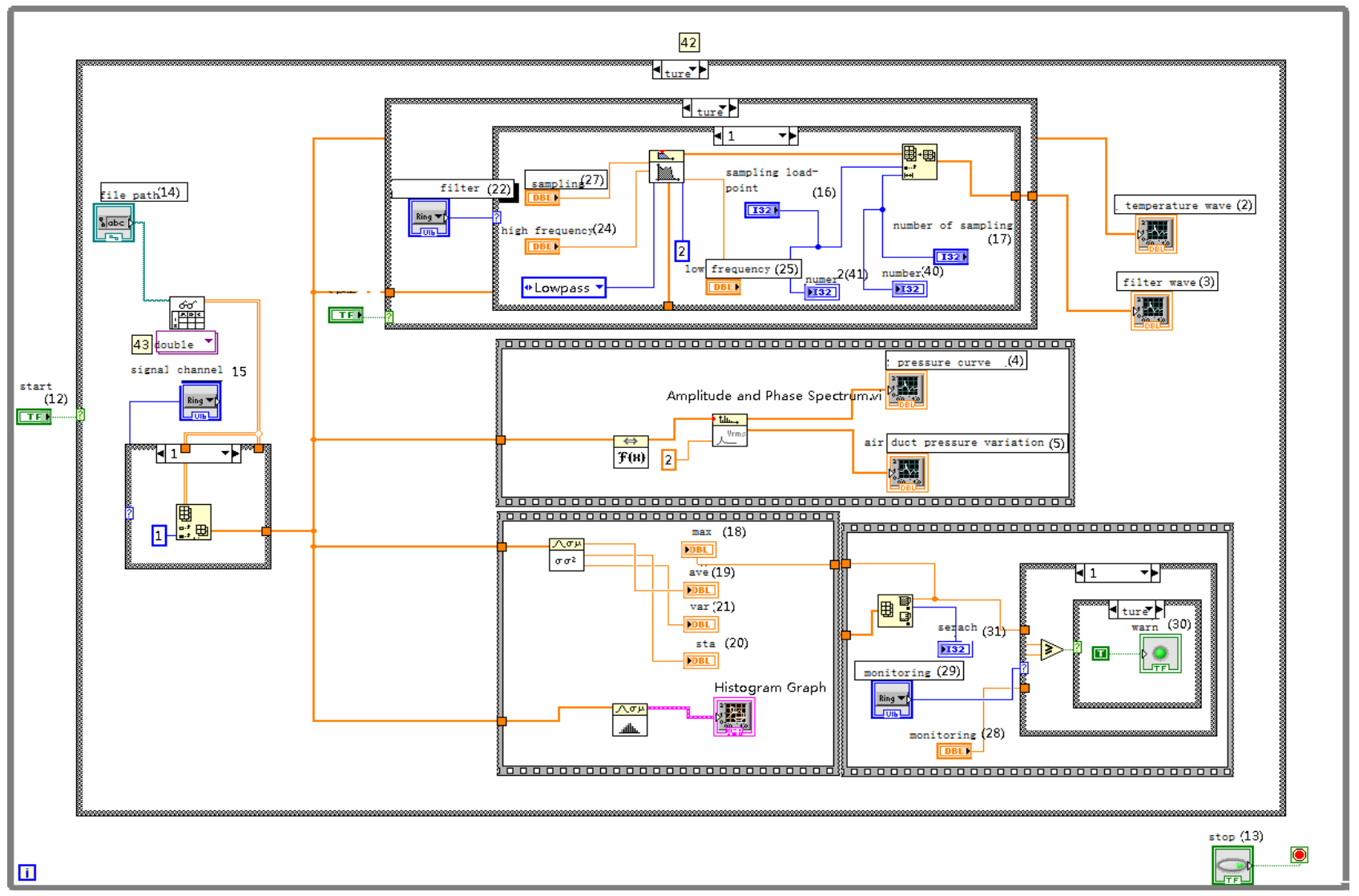

Figure 8. Squash museum indoor temperature monitoring program. 


\section{The Simulation Results and Analysis}

To monitor the squash hall indoor temperature by using the monitoring system, the system sampling number is set as 10,000 , the wave filter type choose chebyshev filter, the high cut-off frequency is 0.45 , the low cutoff frequency is 5.0 , and the monitoring threshold is set up as 4.3. Then click the start run button, and the experiment result is shown in Figure 7. Set the volume flow to be $\mathrm{Q}=390,000$ (centrifugal fan) ${ }^{*} 2 \mathrm{~m}^{3} / \mathrm{h}=780,000 \mathrm{~m}^{3} / \mathrm{h} / 3600=216.7 \mathrm{~m}^{3}$. Do simulation experiments by using Solid Works Flow Simulation [13], and the simulation results are shown in Table 1.

From the simulation results in Table 1, we can know that if the human exposure temperature changes between $20^{\circ} \mathrm{C}$ and $43^{\circ} \mathrm{C}$, then the athletes comfort safety requirements can be achieved in the athletes' playing process. It proves that the monitoring system effectively improves the squash hall indoor temperature control stability. From the monitoring statue in Figure 7, the indoor temperature curve markedly reduced when the alarm lights are on. The decline of indoor pressure difference curve reflects the real-time process of the staff adjusting air condition wind speed, which proves that the practicality of this monitor system is strong and the efficiency is high.

\section{Conclusions}

The system set up for the squash hall indoor temperature monitoring system by using: abVIEW virtue instrument, which can realize real-time monitoring of indoor temperature changes. It has alarm modules and real-time curves. In monitor system modules, when the result of the average temperature of the squash hall divided by ten reaches the monitor threshold, then it can monitor many aspects within indoor squash hall and can prompt the operator to work correctly.

This system can both record the data and process after opening the squash hall in real-time and draw automatically the indoor temperature and pressure curves, which can grasp the best adjustment parameters, and can give specific guidance to operators, which reduces the errors and secures the appropriate sports environment for athletes, and achieves the goal of replacing the traditional monitor instruments by virtue monitor instruments based on software.

Table 1. The simulation results.

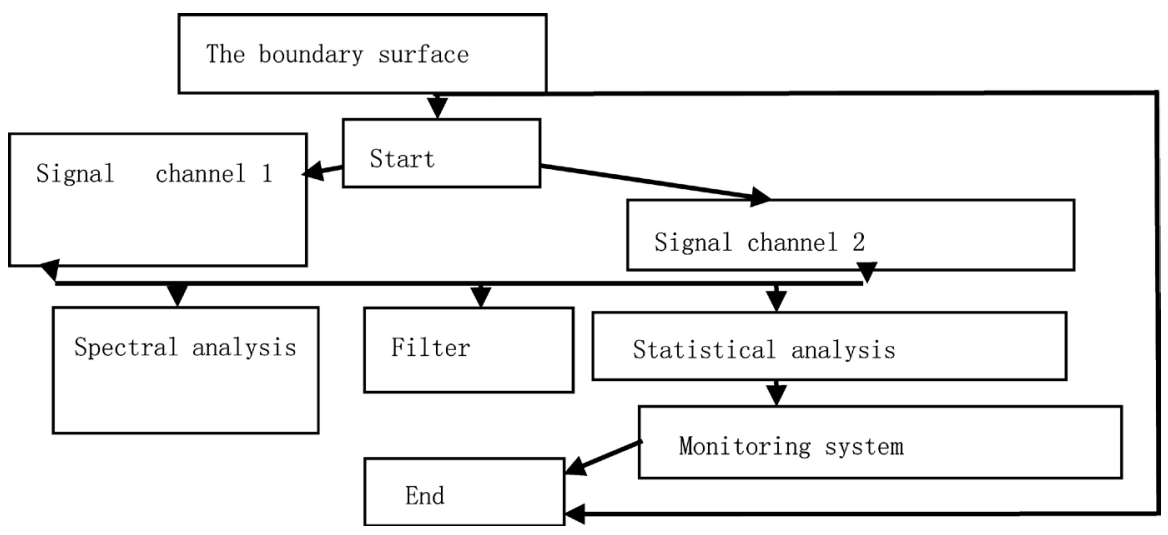


The experiment shows that, by using the system to alarm the squash hall indoor temperature, the athletes' contact temperature changes between $20^{\circ} \mathrm{C}$ and $43^{\circ} \mathrm{C}$ can achieve the comfort and safety requirements of sports. But the problems about too complex interface, complicated software design and perfect match with the existing air conditioning ventilation system in the process of doing experiment, which needs to be improved in the future researches [14].

\section{References}

[1] Nordstrom P., Pettersson, U. and Lorentzon R. (1998) Type of Physical Activity, Muscle Strength, and Pubertal Stage as Determinants of Bone Mineral Density and Bone Area in Adolescent Boys. Journal of Bone and Miner Research, 13, 1141-1148. https://doi.org/10.1359/jbmr.1998.13.7.1141

[2] Pettersson, U., Nordstrom, P., Alfredson, H., Henriksson-Larsen, K. and Lorentzon, R. (2000) Effect of High Impact Activity on Bone Mass and Size in Adolescent Females: A Comparative Study between Two Different Types of Sports. Calcif Tissue International, 67, 207-214. https://doi.org/10.1007/s002230001131

[3] Tian, Y. (2003) Exercise Physiology Advanced Course. Higher Education Press, Beijing.

[4] LI, X., Yang, Z.J. and Sun, Y.H. (2006) LabVIEW Virtual Instrument Technology Applications in Real-Time Monitoring of Micro Drilling System. Machine Tool \& Hydraulics TECHNOLOGY, 35, 153-154.

[5] Wan, Q. and Dai, H.X. (2012) Research on the Squash Tournament. Sports Culture Guide, No. 10, 51-53.

[6] Wang, L., Xiong, Q.Y. and Li, N. (2008) Monitoring Application Research Based on Kingview. Microcomputer Information, 24,111-112.

[7] Arabi, A., Tamim, H. and Nabulsi, M. (2004) Sex Differences in the Effect of Bo Dy-Composition Variables on Bone Mass in Healthy Children and Adolescents. Journal of Clinical Nutrition, 80, 1428-1435.

[8] Xiu, C., Chang, S.X. and Jin, C.H. (2012) For Research and Training Methods of Physical Fitness Squash Player. Neijiang Technology, No. 1, 173-189.

[9] Luan, T., Xue, W.D., Zheng, D. and Hong, Y.J. (2010) Solidification of Polycrystalline Silicon Production Line Monitoring System Based Kingview. Xiamen University (Natural Science), 49, 220-222.

[10] Lei, Z.S. (2008) LabVIEW8.2 Based Tutorial. China Railway Publishing House, Beijing.

[11] Wang, F.J. (2004) Computational Fluid Dynamics Analysis Software-CFD Principles and Applications. Tsinghua University Press, Beijing.

[12] Yang, M. (2008) Optimization of Pipe Flow Friction within Solid Works-Based Analysis. Machine Tool \& Hydraulics, 167-171.

[13] Li, J.M., Li, C.Y., Xu, F.Y. and Zhang, Y. (2013) Three-Dimensional Flow Field Simulation Batch Grain Dryer Heat Cycle-Based on Solid Works. Agricultural Mechanization Research, No. 1, 18-21.

[14] Wang, M.S. and Ma, H.Y (2015) Design and Application of the Online Monitoring System Design Based on the Substation Running Condition. Transactions of China Electrotechnical Society, 30, 484-489. 
Submit or recommend next manuscript to SCIRP and we will provide best service for you:

Accepting pre-submission inquiries through Email, Facebook, LinkedIn, Twitter, etc. A wide selection of journals (inclusive of 9 subjects, more than 200 journals)

Providing 24-hour high-quality service

User-friendly online submission system

Fair and swift peer-review system

Efficient typesetting and proofreading procedure

Display of the result of downloads and visits, as well as the number of cited articles Maximum dissemination of your research work

Submit your manuscript at: http://papersubmission.scirp.org/

Or contact jcc@scirp.org 